\title{
Increased expression of LncRNA BANCR and its prognostic significance in human hepatocellular carcinoma
}

\author{
Tao Zhou and Yanjing Gao*
}

\begin{abstract}
Background: Long noncoding RNAs (InCRNAs) have been proved to play important roles in the tumorigenesis and development of human hepatocellular carcinoma (HCC). The aim of our study is to investigate the expression and function of BRAF-activated noncoding RNA (BANCR) in HCC.

Methods: BANCR expression was detected in HCC tissues and cell lines by using quantitative real-time PCR (qRT-PCR). Association between BANCR levels and clinicopathological factors and patient prognosis was also analyzed. 3-(4,5-Dimethylthiazol-2-yl)-2,5-diphenyl tetrazolium bromide (MTT), flow cytometry, and transwell invasion and migration assays were used to investigate the role of BANCR in the regulation of biological behaviors of HCC cells.

Results: BANCR expression was remarkably increased in HCC tissues compared with adjacent noncancerous tissues $(P<0.001)$. BANCR expression in four HCC cell lines was also significantly upregulated $(P<0.05)$. Clinicopathologic analysis revealed that high BANCR expression correlated with high tumor grade, large tumor size, venous infiltration, advanced tumor, node, and metastasis (TNM) stage, and shorter overall survival. Multivariate regression analysis identified BANCR overexpression as an independent unfavorable prognostic factor (relative risk [RR] 4.245; $P=0.015)$ in HCC patients. Moreover, BANCR downregulation in Hep3B cells impaired cell proliferation, promoted cell apoptosis, reduced cell invasion and migration, led to downregulated vimentin, and upregulated E-cadherin protein levels.
\end{abstract}

Conclusions: These findings suggested that BANCR may contribute to HCC initiation and progression and would be used as not only a novel prognostic marker but also a potential therapeutic target for this disease.

Keywords: Long noncoding RNA, BANCR, Hepatocellular carcinoma, Prognosis

\section{Background}

Hepatocellular carcinoma (HCC) is the fifth most common cancer worldwide, with a constantly increasing frequency, especially in China [1]. Despite recent advances in clinical and experimental oncology, the long-term prognosis of HCC patients remains poor, due to late detection of disease, frequent cancer metastasis, high recurrence rate, and lack of effective therapeutic intervention for terminally staged tumors. Previous studies have revealed many HCC-associated deregulated genes and signaling pathways [2, 3], but

\footnotetext{
* Correspondence: docgaoyj@163.com

Department of Gastroenterology, Qi-Lu Hospital, Shandong University, Jinan 250012, Shan Dong Province, People's Republic of China
}

the highly complex molecular mechanisms underlying its carcinogenesis and progression are still obscure. Therefore, it is urgent to identify reliable biomarkers of $\mathrm{HCC}$ for its early diagnosis, effective therapy, and prognosis evaluation.

Long noncoding RNA (lncRNA), >200 nucleotides in length, is a type of noncoding RNA molecule that can regulate gene expression in transcriptional or posttranscriptional level $[4,5]$. Recent research has shown that lncRNAs participate in a large number of cellular processes, such as cell proliferation, differentiation, apoptosis, and cell cycle progression [6]. Emerging evidence indicates that lncRNAs play important roles in the biology of human cancers, which may provide a new but 
promising way to deal with cancer [7]. Functional lncRNAs may be applied for cancer diagnosis and prognosis and also act as potential novel therapeutic targets. For example, increased expression of lncRNA HOTTIP enhances tumor growth and migration in pancreatic cancer [8]. LncRNA MALAT1 overexpression is a negative prognostic factor for lung cancer [9]. LincRNAs VLDLR, PVT1, and GAS5 could regulate tumor cell responses to chemotherapy [10-12]. However, the understanding of the expression and function of lncRNAs in HCC is still in the early stage.

BRAF-activated noncoding RNA (BANCR), a 693-bp IncRNA, was originally identified in melanoma cells by Flockhart RJ et al. [13]. Subsequently, aberrant lncRNA BANCR expression has been confirmed in papillary thyroid carcinoma [14], retinoblastoma [15], lung cancer [16, 17], gastric cancer [18], and colorectal cancer [19]. In these tumors, BANCR regulated cell proliferation, migration, and invasion and may serve as a potential oncogene or a candidate tumor suppressor. However, no report of BANCR in HCC has been found. In the present study, we examined BANCR expression in HCC tissues and cell lines. We also investigated the correlation between BANCR levels and clinicopathological characteristics and patient's survival. Moreover, we explored the role of BANCR in the regulation of biological behaviors of HCC cells.

\section{Methods}

\section{Patients and clinical specimens}

This study was approved by the Research Ethics Committee of Qi-Lu Hospital. Written informed consent was obtained from all of the patients. All specimens were handled and made anonymous according to the ethical and legal standards.

Matched fresh specimens of HCC and adjacent noncancerous liver tissues were obtained from 109 patients who underwent hepatic resection at Qi-Lu Hospital between January 2008 and March 2010. All tissues were immediately frozen in liquid nitrogen and stored at $-80{ }^{\circ} \mathrm{C}$ until analysis. None of the patients had undergone chemotherapy or radiotherapy before surgery. Details of clinical and pathological characteristics of the patients are summarized in Table 1. Follow-up data were available for all patients. Overall survival was defined as the amount of time from the day of primary surgery to the date of death or the end of follow-up (for living patients).

\section{Cell culture and RNA interference}

Human HCC cell lines (HuH-7, Hep3B, HepG2, and $\mathrm{H} 2-\mathrm{M}$ ) and human normal hepatocyte CL-48 were obtained from the Institute of Biochemistry and Cell Biology of the Chinese Academy of Sciences (Shanghai,
China). The cells were maintained in high glucose (4.5 g/l) Dulbecco's modified Eagle's medium (DMEM; Gibco-BRL, Gaithersburg, MD) supplemented with $10 \%$ heat-inactivated fetal bovine serum (FBS), $100 \mathrm{U} / \mathrm{ml}$ of penicillin and $100 \mu \mathrm{g} / \mathrm{ml}$ streptomycin sulfate. Cultures were incubated in a humidified atmosphere of $5 \% \mathrm{CO}_{2}$ at $37^{\circ} \mathrm{C}$.

lncRNA BANCR small interfering RNA (si-BANCR) and nontargeting small interfering RNA (siRNA) (si-NC) were purchased from Sigma-Aldrich. HCC cells were transfected with siRNA by using Lipofectamine 2000 (Invitrogen, CA, USA) according to the manufacturer's instructions. The cells were harvested for further assays $48 \mathrm{~h}$ after transfection.

\section{RNA extraction, reverse transcription, and qRT-PCR}

Total RNA was extracted using the Trizol reagent (Invitrogen, Carlsbad, CA) according to the manufacturer's instructions. RNA was reverse transcribed into cDNA using the Prime-Script one step RT-PCR kit (Takara, Dalian, China). BANCR expression levels were measured with quantitative real-time PCR (qRT-PCR) using an ABI7500 system and the SYBR Green PCR Master Mix (Takara). Glyceraldehyde-3-phosphate dehydrogenase (GAPDH) was used as an internal control. The primer sequences for BANCR were $5^{\prime}$-ACAGG ACTCCATGGCAAACG-3' (forward) and 5'-ATGAAG AAAGCCTGGTGCAGT-3' (reverse). Each assay was performed in triplicate, and relative BANCR expression was normalized to GAPDH using the $2^{-\Delta \mathrm{Ct}}$ method.

\section{Cell proliferation assay}

Cell proliferation was analyzed using MTT assay. Briefly, approximately $1 \times 10^{3}$ cells were seeded into a 96-well plate and incubated for 1, 2, 3, and 4 days. At the indicated time point, $20 \mu \mathrm{l}$ of MTT ( $5 \mathrm{mg} / \mathrm{ml}$ ) (Sigma, USA) was added into each well and incubated for another $4 \mathrm{~h}$. Then, the supernatants were removed, and $150 \mu \mathrm{l}$ of DMSO (Sigma, USA) was added to terminate the reaction. The absorbance value (OD) was measured at $490 \mathrm{~nm}$ on a microplate reader (Molecular Devices, Sunnyvale, CA, USA).

\section{Detection of apoptosis by flow cytometry}

Forty-eight hours after transfection, the HCC cells were harvested, washed, and resuspended in ice-cold PBS. The cells were then treated with propidium iodide $(10 \mu \mathrm{g} / \mathrm{ml}$; Sigma) and Annexin V-FITC $(50 \mu \mathrm{g} / \mathrm{ml}, \mathrm{BD})$ in the dark for $15 \mathrm{~min}$ at room temperature and examined by flow cytometry (FACScan; BD Biosciences).

\section{Cell invasion and migration assays}

Six-well transwell chambers $(8-\mu \mathrm{m}$ pore size, Corning, New York, USA) were used to investigate cell invasion 
Table 1 Correlation between BANCR expression and different clinicopathological features in patients with hepatocellular carcinoma

\begin{tabular}{|c|c|c|c|c|}
\hline \multirow[t]{2}{*}{ Clinicopathological features } & \multirow[t]{2}{*}{ No. of cases } & \multicolumn{2}{|c|}{ BANCR expression } & \multirow[t]{2}{*}{$P$} \\
\hline & & Low $(n, \%)$ & High $(n, \%)$ & \\
\hline \multicolumn{5}{|l|}{ Age } \\
\hline$<60$ & 53 & $29(54.7 \%)$ & $24(45.3 \%)$ & \multirow[t]{2}{*}{0.845} \\
\hline$\geq 60$ & 56 & $26(46.4 \%)$ & $30(53.6 \%)$ & \\
\hline \multicolumn{5}{|l|}{ Gender } \\
\hline Male & 80 & $39(48.8 \%)$ & $41(51.2 \%)$ & \multirow[t]{2}{*}{0.666} \\
\hline Female & 29 & $16(55.2 \%)$ & $13(44.8 \%)$ & \\
\hline \multicolumn{5}{|l|}{ Tumor grade } \\
\hline G1 & 34 & $24(70.6 \%)$ & $10(29.4 \%)$ & \multirow[t]{2}{*}{0.007} \\
\hline $\mathrm{G} 2+\mathrm{G} 3$ & 75 & $31(41.3 \%)$ & $44(58.7 \%)$ & \\
\hline \multicolumn{5}{|l|}{ AFP (ng/L) } \\
\hline$\geq 400$ & 61 & $27(44.4 \%)$ & $34(55.6 \%)$ & \multirow[t]{2}{*}{0.178} \\
\hline$<400$ & 48 & $28(58.3 \%)$ & $20(41.7 \%)$ & \\
\hline \multicolumn{5}{|l|}{ With cirrhosis } \\
\hline Yes & 74 & $36(48.6 \%)$ & $38(51.4 \%)$ & \multirow[t]{2}{*}{0.683} \\
\hline No & 35 & $19(54.3 \%)$ & $16(45.7 \%)$ & \\
\hline \multicolumn{5}{|l|}{ Tumor diameter (cm) } \\
\hline$<5$ & 66 & $41(62.1 \%)$ & $25(37.9 \%)$ & \multirow[t]{2}{*}{0.003} \\
\hline$\geq 5$ & 43 & $14(32.6 \%)$ & $29(67.4 \%)$ & \\
\hline \multicolumn{5}{|l|}{ Tumor nodes } \\
\hline Multi & 37 & $15(40.5 \%)$ & $22(59.5 \%)$ & \multirow[t]{2}{*}{0.16} \\
\hline Single & 72 & $40(55.6 \%)$ & $32(44.4 \%)$ & \\
\hline \multicolumn{5}{|l|}{ Venous infiltration } \\
\hline Presence & 39 & $11(28.2 \%)$ & $28(71.8 \%)$ & \multirow[t]{2}{*}{0.001} \\
\hline Absence & 70 & $44(62.9 \%)$ & $26(37.1 \%)$ & \\
\hline \multicolumn{5}{|l|}{ TNM stage } \\
\hline $1+1 \mid$ & 51 & $34(66.7 \%)$ & $17(33.3 \%)$ & \multirow[t]{2}{*}{0.002} \\
\hline III & 58 & $21(36.2 \%)$ & 37 (66.8 \%) & \\
\hline
\end{tabular}

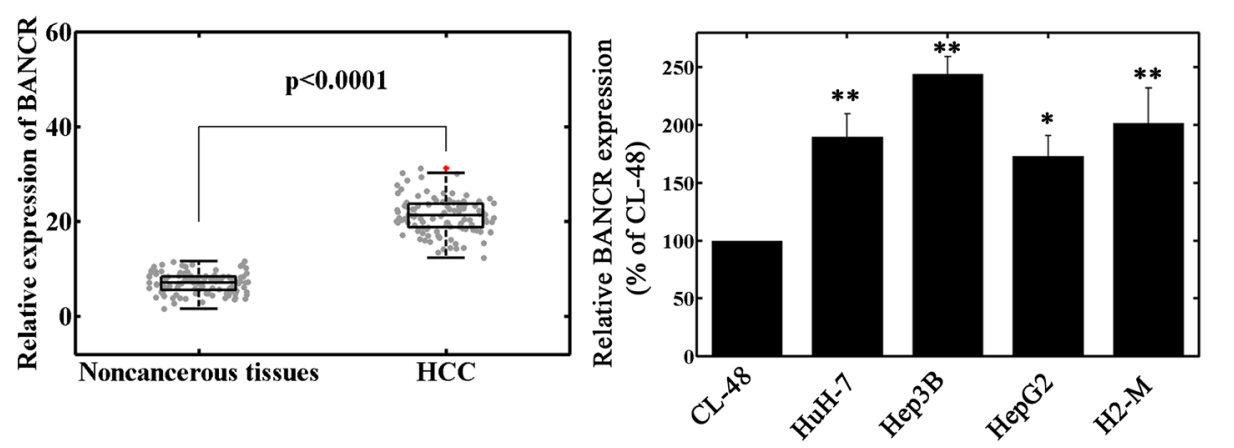

Fig. 1 Relative BANCR expression levels in hepatocellular carcinoma (HCC) tissues and cell lines. BANCR expression was calculated by the $2^{-\Delta C t}$ method and normalized to GAPDH. a BANCR expression was significantly higher in HCC tissues than in the corresponding noncancerous tissues. b BANCR expression was upregulated in human HCC cell lines compared to normal hepatocyte CL-48O cells. ${ }^{*} P<0.05$; ${ }^{* *} P<0.01$ 


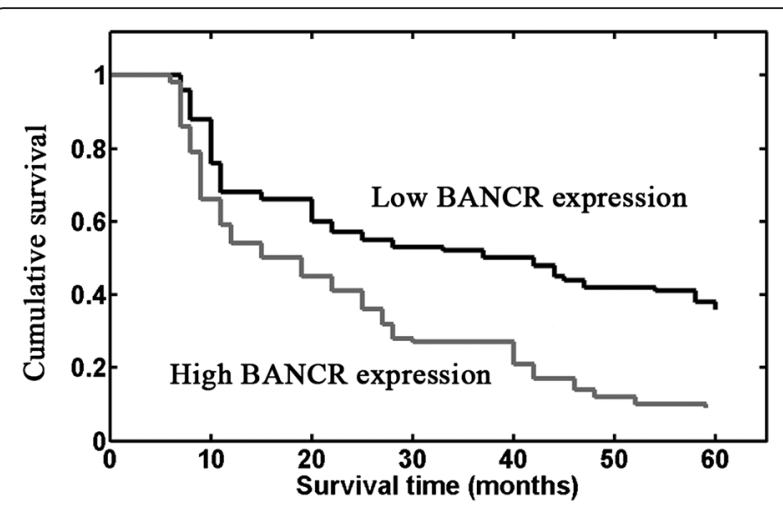

Fig. 2 Kaplan-Meier curves for overall survival of 109 hepatocellular carcinoma patients, divided according to BANCR expression levels. High BANCR expression was significantly associated with poor survival $(P<0.001$, log-rank test)

and migration. For migration assay, about $1 \times 10^{5} \mathrm{HCC}$ cells in serum-free media were seeded into the upper chambers after siRNA transfection. The lower chamber contained medium with $20 \%$ FBS to stimulate migration. Following a $48 \mathrm{~h}$-incubation, the cells located on the lower surface of the chamber were fixed with $95 \%$ ethanol for $10 \mathrm{~min}$, stained with $0.1 \%$ crystal violet for $20 \mathrm{~min}$, and counted using a microscope (Olympus Corp., Tokyo, Japan). For invasion assay, the upper chambers were first covered with $5 \mathrm{mg} / \mathrm{ml} \mathrm{Matrigel,} \mathrm{and} \mathrm{the} \mathrm{other} \mathrm{steps} \mathrm{were} \mathrm{the} \mathrm{same}$ as migration.

\section{Western blot}

Cells were lysed in RIPA buffer with protease inhibitors and phosphatase inhibitors. The protein extracts were loaded onto a $10 \%$ sodium SDS-PAGE gel and transferred to a PVDF membrane. The blots were probed with primary antibodies (Cell signal technology, USA) followed by the HRP-conjugated secondary antibody. Following three Tris-buffered saline containing $0.1 \%$
Tween-20 (TBST) washes, the membranes were developed using ECL Plus (Millipore, MA, USA) and exposed to X-ray film. GAPDH served as the loading control.

\section{Statistics}

All statistical analyses were performed using the SPSS 16.0 software package (SPSS, Chicago, IL, USA). The significance of differences between groups was estimated by Student's $t$ test and chi-square test. Survival curves were constructed with the Kaplan-Meier method and compared by the log-rank test. The significance of survival variables was evaluated using a multivariate Cox proportional hazards regression analysis. $P<0.05$ was considered statistically significant.

\section{Results}

Increased BANCR expression in HCC tissues and cell lines BANCR expression in HCC tissues and cell lines was measured by qRT-PCR. Figure 1a showed a significant high expression of BANCR in HCC tissues compared with adjacent noncancerous tissues $(P<0.001)$. BANCR expression in four HCC cell lines was also clearly upregulated (Fig 1b, $P<0.05$ ). The Hep3B cell line, which possessed the highest BANCR expression among all tested cell lines, was chosen for the subsequent in vitro experiments.

\section{Association between clinicopathological characteristics and BANCR expression in HCC patients}

We further analyzed the association between BANCR expression and clinicopathological characteristics of HCC. HCC samples were classified into low BANCR expression group $(n=55)$ and the high BANCR expression group $(n=54)$ according to the median BANCR expression level of all HCC samples. The association between clinicopathological characteristics and BANCR expression was summarized in Table 1. We found that high

Table 2 Univariate and multivariate analysis of overall survival in 109 patients with hepatocellular carcinoma

\begin{tabular}{|c|c|c|c|c|}
\hline \multirow[t]{2}{*}{ Variables } & \multicolumn{2}{|c|}{ Univariate analysis } & \multicolumn{2}{|c|}{ Multivariate analysis } \\
\hline & $\mathrm{RR}$ & $P$ value & $\mathrm{RR}$ & $P$ value \\
\hline Age (years) $(\geq 60 /<60)$ & 0.785 & 0.323 & - & - \\
\hline Gender (male/female) & 0.721 & 0.455 & - & - \\
\hline Tumor grade (G1/G2 + G3) & 2.387 & 0.037 & 0.795 & 0.146 \\
\hline $\operatorname{AFP}(n g / l)(\geq 400 /<400)$ & 0.816 & 0.194 & - & - \\
\hline With cirrhosis (yes/no) & 0.904 & 0.092 & - & - \\
\hline Tumor diameter $(\mathrm{cm})(\geq 5 /<5)$ & 3.252 & 0.025 & 2.655 & 0.039 \\
\hline Tumor nodes (multi/single) & 0.868 & 0.156 & - & - \\
\hline Venous infiltration (presence/absence) & 5.153 & 0.008 & 3.278 & 0.022 \\
\hline TNM stage (I-II/III) & 6.225 & $<0.001$ & 6.379 & 0.006 \\
\hline Expression of BANCR (low/high) & 5.983 & $<0.001$ & 4.245 & 0.015 \\
\hline
\end{tabular}




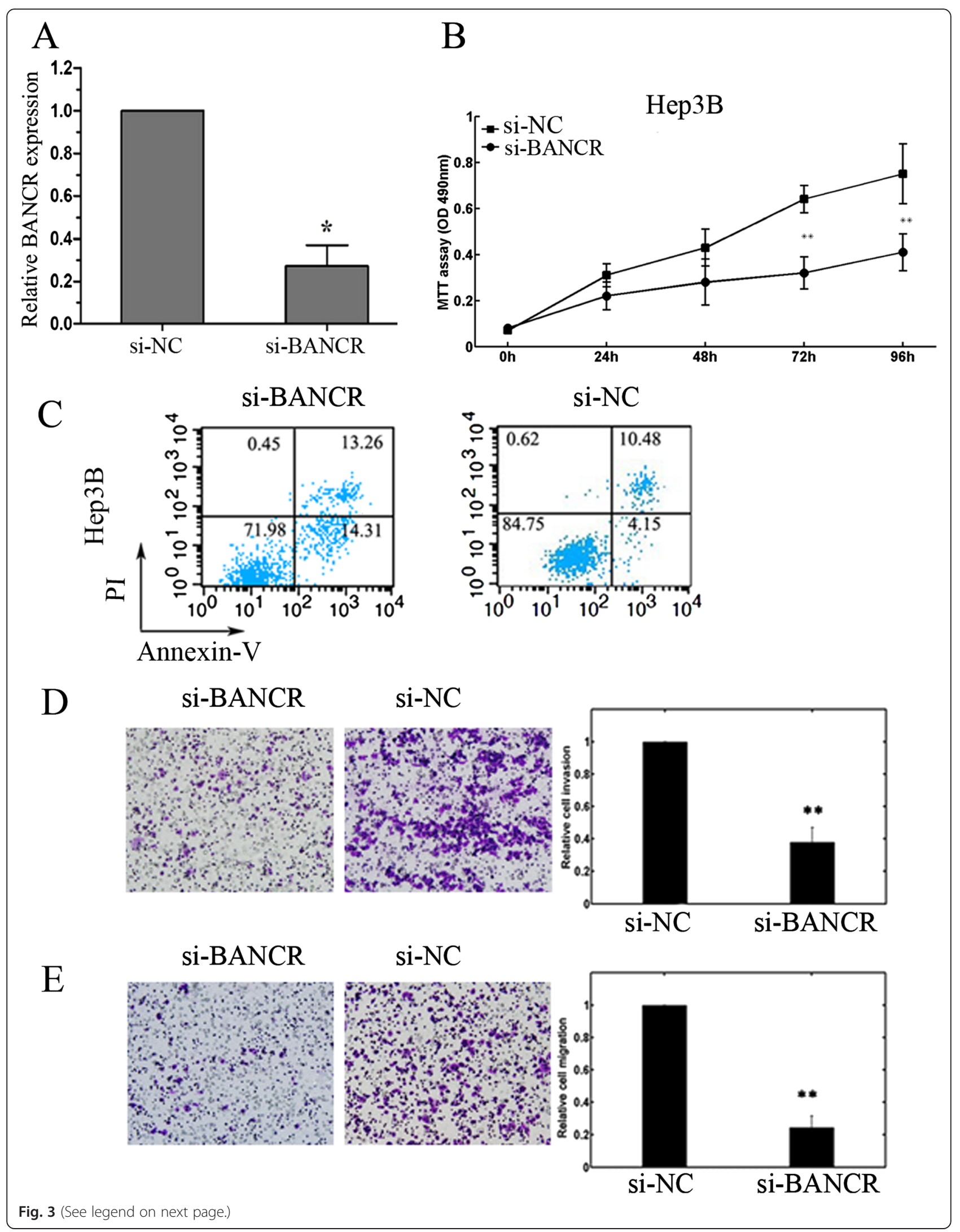


(See figure on previous page.)

Fig. 3 Effects of BANCR on the biological behaviors of Hep3B cells. a qRT-PCR analysis confirmed decreased BANCR expression in Hep3B cells after si-BANCR transfecting. BANCR expression was normalized to GAPDH. ${ }^{*} P<0.05$. b Cell proliferation was measured by MTT assay in Hep3B cells transfected with si-BANCR or si-NC. ${ }^{* *} P<0.01$. c Flow cytometric analysis showed induced cell apoptosis after si-BANCR transfection. $\mathbf{d}$, e Transwell invasion and migration assays showed that the number of invaded/migrated cells was significantly lower in the si-BANCR-transfected group than in the si-NC-transfected group. ${ }^{* *} P<0.01$

BANCR expression levels were closely correlated with high tumor grade $(P=0.007)$, large tumor size $(P=$ $0.003)$, venous infiltration $(P=0.001)$, and advanced tumor, node, and metastasis (TNM) stage $(P=0.002)$. No significant difference was observed between BANCR expression and other clinical features such as patients' age, gender, cirrhosis, serum AFP level, and number of tumor nodules.

\section{Prognostic values of BANCR expression in HCC patients} Then, we evaluated whether BANCR expression had prognostic potential for overall survival of HCC patients. Using the Kaplan-Meier method and log-rank test, the overall survival of patients with high BANCR expression was significantly shorter than those with low BANCR expression $(P<0.001$; Fig. 2$)$. Besides, the survival benefits were also found in those with small tumor diameter $(P=0.025)$, well tumor differentiation $(P=0.037)$, negative venous invasion $(P=0.008)$, and early TNM stage $(P<0.001$; Table 2).

Multivariate Cox regression analysis enrolling the abovementioned significant parameters revealed that BANCR expression (relative risk [RR] 4.245; $P=0.015$ ), tumor size (RR 2.655; $P=0.039$ ), venous infiltration (RR 3.278; $P=0.022$ ), and TNM stage (RR 6.379; $P=0.006$ ) were independent prognostic markers for overall survival of HCC patients (Table 2).

\section{Effects of BANCR downregulation on the biological behaviors of Hep3B cells}

At last, we explored the role of BANCR in regulating the biological behaviors of $\mathrm{HCC}$ cells. BANCR expression in Hep3B cells was evidently downregulated after siBANCR transfection (Fig 3a). As shown in Fig. 3b, c,
BANCR downregulation impaired Hep3B cell proliferation and promoted cell apoptosis compared to the si-NC group. In addition, the invasion and migration ability of Hep3B cells was significantly reduced after si-BANCR transfection (Fig 3d, e).

\section{BANCR induces Epithelial-to-mesenchymal transition (EMT) phenotypes}

To explore the potential underlying mechanisms of BANCR-related high cell migration, we detected the changes in E-cadherin and vimentin protein levels after si-BANCR transfection by Western blot. The results showed that BANCR downregulation in Hep3B cells was associated with upregulated E-cadherin and downregulated vimentin protein levels (Fig. 4).

\section{Discussion}

Identifying novel molecules that take part in HCC formation and progression may be helpful for improving the diagnosis, prevention, and treatment of this disease. The relationship between lncRNAs and tumors has currently become one of the focuses of cancer studies. Abnormal expression of several lncRNAs has been reported in HCC. For example, IncRNA AOC4P overexpression in HCC cells significantly reduced cell proliferation, migration, and invasion by inhibiting the epithelialmesenchymal transition (EMT) [20]. IncRNA UCA1 was aberrantly upregulated in HCC tissues and associated with TNM stage, metastasis, and postoperative survival [21]. UCA1 depletion inhibited the growth and metastasis of HCC cell lines in vitro and in vivo. Serum IncRNA-AF085935 was helpful to discriminate HCC from hepatitis $B$ viral infected patients and healthy controls [22]. Injection of the IncRNA PTENP1-expressing

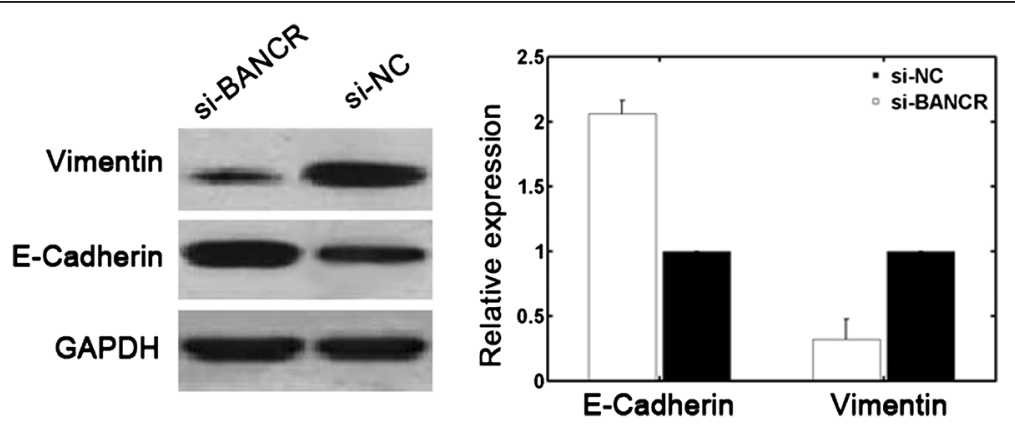

Fig. 4 BANCR downregulation in Hep3B cells was associated with decreased vimentin and increased E-cadherin protein levels 
vectors into mice bearing $\mathrm{HCC}$ tumors effectively mitigated the tumor growth, suppressed intratumoral cell proliferation, elicited apoptosis, autophagy and inhibited angiogenesis [23]. These findings suggested that lncRNAs might play important roles in HCC initiation and development and have a great potential for clinical application.

In the present study, we observed a high BANCR expression in $\mathrm{HCC}$ specimens and cell lines, providing the first evidence that BANCR overexpression was closely associated with HCC carcinogenesis. Then, we correlated increased BANCR levels with aggressive clinicopathological features of HCC tissues. Downregulation of BANCR in Hep3B cells would reduce cell proliferation, enhance cell apoptosis, and impair cell invasion and migration. These findings revealed that BANCR might be involved in $\mathrm{HCC}$ progression and contribute to molecular-targeted therapy. In addition, our research showed that HCC patients with high BANCR levels tended to have shorter overall survival than patients with lower levels. Multivariate Cox hazard regression analysis identified high BANCR expression as an independent indicator of unfavorable prognosis. To our knowledge, this is the first study to analyze the expression and clinical significance of BANCR in HCC.

BANCR has been reported as an oncogene in several types of human malignancies. BANCR levels in human malignant melanoma tissues increased with advanced tumor stages, and the knockdown of BANCR suppressed melanoma cell proliferation and migration through MAPK pathway [13, 24]. BANCR overexpression correlated with tumor stage and lymph node metastasis in colorectal cancer and contributed to cancer cell migration through inducing epithelial-mesenchymal transition. In gastric cancer, BANCR expression was increased in tumor tissues compared with paired adjacent normal tissues. High BANCR levels were positively associated with clinical stage, tumor depth, lymph node and distant metastasis, and poor prognosis [18]. In retinoblastoma, BANCR regulated cell proliferation, migration, and invasion in vitro and overexpressed BANCR expression linked with tumor size, choroidal invasion, and optic nerve invasion [15].

In contrast to the tumor-promoting properties mentioned above, Sun et al. reported that BANCR was obviously downregulated in non-small cell lung cancer tissues and that reduced BANCR expression was associated with larger tumor size, lymph node metastasis, advanced TNM stage, and shorter overall survival. Ectopic expression of BANCR impaired cell viability and invasion, leading to the inhibition of metastasis in vitro and in vivo [16]. Taken together, the role of lncRNA BANCR in human malignancies may be multifaceted and determined by the distinct context in various microenvironments.
EMT is one of the key processes for primary tumor cells to acquire a migratory capacity [25]. Reduced Ecadherin expression and increased vimentin expression are associated with $\mathrm{HCC}$ progression [26, 27]. Emerging evidence demonstrates that lncRNAs, including BANCR, may regulate EMT processes in several cancer types [19, 28-30]. In the present study, BANCR downregulation resulted in upregulated E-cadherin and downregulated vimentin protein levels. These findings indicated that BANCR might be involved in the regulation of EMT in HCC, providing a possible explanation for BANCR-related high cell migration.

\section{Conclusions}

In conclusion, our research confirmed increased BANCR expression in HCC tissues and cell lines. Our study also showed that high BANCR levels correlated tumor progression and poor prognosis. Regulation of BANCR expression influenced biological behaviors of HCC cells. These findings suggested that BANCR may act as an oncogene in HCC initiation and development and would be not only a novel prognostic marker but also a potential therapeutic target for this disease.

\section{Competing interest}

The authors declare that they have no competing interests.

\section{Authors' contributions}

TZ and YG conceived, designed, and performed the experiments. TZ analyzed the data. YG contributed to the reagents, materials, and analysis tools. TZ and YG wrote the paper. Both authors read and approved the final manuscript.

Received: 9 September 2015 Accepted: 30 December 2015

Published online: 12 January 2016

\section{References}

1. Parkin DM, Bray F, Ferlay J, Pisani P. Global cancer statistics, 2002. CA Cancer J Clin. 2005:55(2):74-108.

2. Cartularo L, Laulicht F, Sun H, Kluz T, Freedman JH, Costa M. Gene expression and pathway analysis of human hepatocellular carcinoma cells treated with cadmium. Toxicol Appl Pharmacol. 2015;288(3):399-408.

3. Li QF, Li QY, Gao AR, Shi QF. Correlation between promoter methylation in the GSTP1 gene and hepatocellular carcinoma development: a metaanalysis. Genet Mol Res: GMR. 2015;14(2):6762-72.

4. Guttman M, Rinn JL. Modular regulatory principles of large non-coding RNAs. Nature. 2012;482(7385):339-46.

5. Cheetham SW, Gruhl F, Mattick JS, Dinger ME. Long noncoding RNAs and the genetics of cancer. Br J Cancer. 2013;108(12):2419-25.

6. Mercer TR, Dinger ME, Mattick JS. Long non-coding RNAs: insights into functions. Nat Rev Genet. 2009;10(3):155-9.

7. Gibb EA, Brown CJ, Lam WL. The functional role of long non-coding RNA in human carcinomas. Mol Cancer. 2011;10:38.

8. Cheng Y, Jutooru I, Chadalapaka G, Corton JC, Safe S. The long non-coding RNA HOTTIP enhances pancreatic cancer cell proliferation, survival and migration. Oncotarget. 2015;6(13):10840-52.

9. Zhang J, Zhang B, Wang T, Wang H. LnCRNA MALAT1 overexpression is an unfavorable prognostic factor in human cancer: evidence from a metaanalysis. Int J Clin Exp Med. 2015;8(4):5499-505.

10. You L, Chang D, Du HZ, Zhao YP. Genome-wide screen identifies PVT1 as a regulator of Gemcitabine sensitivity in human pancreatic cancer cells. Biochem Biophys Res Commun. 2011:407(1):1-6. 
11. Takahashi K, Yan IK, Wood J, Haga H, Patel T. Involvement of extracellular vesicle long noncoding RNA (linc-VLDLR) in tumor cell responses to chemotherapy. Mol Cancer Res. 2014;12(10):1377-87.

12. Pickard MR, Williams GT. Regulation of apoptosis by long non-coding RNA GAS5 in breast cancer cells: implications for chemotherapy. Breast Cancer Res Treat. 2014;145(2):359-70.

13. Flockhart RJ, Webster DE, Qu K, Mascarenhas N, Kovalski J, Kretz M, et al. BRAFV600E remodels the melanocyte transcriptome and induces BANCR to regulate melanoma cell migration. Genome Res. 2012;22(6):1006-14.

14. Wang Y, Guo Q, Zhao Y, Chen J, Wang S, Hu J, et al. BRAF-activated long non-coding RNA contributes to cell proliferation and activates autophagy in papillary thyroid carcinoma. Oncol Lett. 2014;8(5):1947-52.

15. Su S, Gao J, Wang T, Wang J, Li H, Wang Z. Long non-coding RNA BANCR regulates growth and metastasis and is associated with poor prognosis in retinoblastoma. Tumour Biol: J Int Soc Oncodevelopmental Biol Med. 2015; 36(9):7205-7211

16. Sun M, Liu XH, Wang KM, Nie FQ, Kong R, Yang JS, et al. Downregulation of BRAF activated non-coding RNA is associated with poor prognosis for nonsmall cell lung cancer and promotes metastasis by affecting epithelialmesenchymal transition. Mol Cancer. 2014;13:68.

17. Jiang $W$, Zhang $D, X u B, W u Z$, Liu S, Zhang $L$, et al. Long non-coding RNA BANCR promotes proliferation and migration of lung carcinoma via MAPK pathways. Biomed Pharmacother $=$ Biomedecine \& pharmacotherapie. 2015:69:90-5.

18. Li L, Zhang L, Zhang Y, Zhou F. Increased expression of LncRNA BANCR is associated with clinical progression and poor prognosis in gastric cancer. Biomed Pharmacother. 2015;72:109-12.

19. Guo Q, Zhao Y, Chen J, Hu J, Wang S, Zhang D, et al. BRAF-activated long non-coding RNA contributes to colorectal cancer migration by inducing epithelial-mesenchymal transition. Oncol Lett. 2014;8(2):869-75.

20. Wang TH, Lin YS, Chen Y, Yeh CT, Huang YL, Hsieh TH, Et al. Long noncoding RNA AOC4P suppresses hepatocellular carcinoma metastasis by enhancing vimentin degradation and inhibiting epithelial-mesenchymal transition. Oncotarget. 2015;6(27):23342-23357.

21. Wang F, Ying $H Q$, He BS, Pan $Y Q$, Deng QW, Sun $H L$, et al. Upregulated IncRNA-UCA1 contributes to progression of hepatocellular carcinoma through inhibition of miR-216b and activation of FGFR1/ERK signaling pathway. Oncotarget. 2015;6(10):7899-917.

22. Lu J, Xie F, Geng L, Shen W, Sui C, Yang J. Investigation of serum IncRNAuc003wbd and IncRNA-AF085935 expression profile in patients with hepatocellular carcinoma and HBV. Tumour Biol. 2015;36(5):3231-6.

23. Chen CL, Tseng YW, Wu JC, Chen GY, Lin KC, Hwang SM, et al. Suppression of hepatocellular carcinoma by baculovirus-mediated expression of long non-coding RNA PTENP1 and MicroRNA regulation. Biomaterials. 2015:44:71-81

24. Li R, Zhang L, Jia L, Duan Y, Li Y, Bao L, et al. Long non-coding RNA BANCR promotes proliferation in malignant melanoma by regulating MAPK pathway activation. PLoS One. 2014;9(6):e100893.

25. Thiery JP, Acloque H, Huang RY, Nieto MA. Epithelial-mesenchymal transitions in development and disease. Cell. 2009:139(5):871-90.

26. Chen J, Zhao J, Ma R, Lin H, Liang X, Cai X. Prognostic significance of Ecadherin expression in hepatocellular carcinoma: a meta-analysis. PLoS One. 2014;9(8):e103952

27. Hu L, Lau SH, Tzang CH, Wen JM, Wang W, Xie D, et al. Association of Vimentin overexpression and hepatocellular carcinoma metastasis. Oncogene. 2004;23(1):298-302.

28. Wang $T H$, Lin $Y S$, Chen $Y$, Yeh $C T$, Huang $Y L$, Hsieh TH, et al. Long noncoding RNA AOC4P suppresses hepatocellular carcinoma metastasis by enhancing vimentin degradation and inhibiting epithelial-mesenchymal transition. Oncotarget. 2015;6(27):23342-57.

29. Wu ZH, Wang XL, Tang HM, Jiang T, Chen J, Lu S, et al. Long non-coding RNA HOTAIR is a powerful predictor of metastasis and poor prognosis and is associated with epithelial-mesenchymal transition in colon cancer. Oncol Rep. 2014;32(1):395-402

30. Zhou X, Liu S, Cai G, Kong L, Zhang T, Ren Y, et al. Long non coding RNA MALAT1 promotes tumor growth and metastasis by inducing epithelialmesenchymal transition in oral squamous cell carcinoma. Sci Rep. 2015;5:15972.

\section{Submit your next manuscript to BioMed Central and we will help you at every step:}

- We accept pre-submission inquiries

- Our selector tool helps you to find the most relevant journal

- We provide round the clock customer support

- Convenient online submission

- Thorough peer review

- Inclusion in PubMed and all major indexing services

- Maximum visibility for your research

Submit your manuscript at www.biomedcentral.com/submit

) Biomed Central 